\title{
Preparation and investigation of composite phase change materials with porous matrixes"
}

\author{
Yang Lan, Xiao-Qin Zhu ${ }^{\dagger}$, Li-Meng Chen, Fu-Guo Wang, \\ Yu Bie and Jing-Hua Chang \\ Faculty of Chemical Engineering, \\ Kunming University of Science and Technology, \\ Kunming, 650500, China \\ tE-mail:xiaoqinzhu@sohu.com
}

\begin{abstract}
Energy and environmental problems have become the key factors restricting social development during the recent years. Therefore, in order to promote the process of social industrialization and build a saving-oriented society, it is imperative to increase the effort to develop energy-saving materials. Phase change materials can solve the problem that energy supply and demand don't match in time and space, and improve the energy efficiency. They are a type of ideal energy-saving materials, combined with a suitable porous matrix to strengthen the process of heat storage and discharge. A review on preparation and investigation of composite phase change materials with porous matrixes was made in this paper, in which the preparation methods, the selection of porous matrixes and their practical applications in various fields were analyzed.
\end{abstract}

Keywords: Composite Phase Change Materials; Porous Matrixes; Preparation; Investigation; Phase Change Energy Storage.

\section{Introduction}

During the recent years, the process of society industrialization is being continuously promoted; energy and environmental problems have become the key factors to restrict the development of the society. Therefore, in order to accelerate social industrialization course and build a saving-oriented society, the development and investigation of energy-saving materials are imperative. Moreover, phase change materials can be utilized to absorb or release energy in the process of their phase transition to solve the match contradiction of supply and demand in time and space, as a type of relatively ideal energy-saving materials, they have been applied in such fields as building materials, aviation, textiles, agriculture, etc[1].

\footnotetext{
${ }^{*}$ This work is financially supported by China National Natural Science Foundation (51066001) and China National Natural Science Foundation (U1137604).
} 
Phase change materials have a lot of species and their existing forms are also varied. According to their phase transition form, they can be divided into solid-liquid type, solid-solid type, solid-gas type and liquid-gas type. Since solid-liquid phase change materials have larger quantity of phase transition latent heat with smaller volume change, they are currently the main research direction. In solid-liquid phase change materials, they can be divided into the two categories, or inorganic phase and organic ones according to their chemical compositions [2].

Solid-liquid phase change materials can be composite with appropriate porous matrixes, which would strengthen the process of heat storage and discharge, and solve the problem of leakage and corrosion of phase change materials. At the same time, this technique is relatively simple, and can achieve production expansion. Therefore, porous composite phase change materials were analyzed from their preparation methods, the selection of porous matrixes and their practical applications in various fields.

\section{Preparation Methods of Porous Composite Phase Change Materials}

Porous matrixes always have higher porosity to use as matrix mediums, they can store the particles of phase change materials as much as possible with the aid of capillary effect, and the particles cannot leak out in the process of phase transition. Simultaneously, their thermal conductivity has higher efficiency, which can strengthen heat transfer efficiency of the phase change materials. At present, the preparation methods of porous composite phase change materials are mostly direct immersion method and vacuum impregnation method.

\subsection{Direct immersion method}

Direct immersion method is usually to soak porous matrix in the solution of phase change material, and to prepare porous composite phase change material with a stable shape, which may not need container to load, thus reducing the unit charge of thermal energy storage. Direct immersion method has such characteristics as simpler technique and easier operation etc. There are a lot of researchers to prepare porous composite phase change materials with this method. i.e. Chahroudi [3] adopted direct immersion method to prepare phase change concrete with Glauber salt and other inorganic phase change materials early in 1970s, but this type of phase change material has a corrosion effect on the concrete substrate. H. Kaasinen [4] seeped polyols and carboxylic acid into porous wall board by direct immersion method, the energy storage density of the two materials was increased greatly, and carboxylic acid in the porous wall board had a greater storage capacity. T. Lee et al[5] prepared phase change 
concrete by direct immersion method, compared the influence of thermal storage performance and air velocity to heat absorption and release between the ordinary concrete and the phase change concrete.

Although direct immersion method is easier to operate, it often requires longer operation time, and the adsorption rate of porous matrix is also lower. The reason is that there is large amount of compressed air inside the porous matrix, which may hinder the liquid to penetrate inside the porous matrix. Therefore, direct immersion method is almost not used at present, and is replaced by vacuum impregnation method.

\subsection{Vacuum impregnation method}

Vacuum impregnation method is to make porous matrix immersed in the melted phase change material with liquid state, after the phase change material is sucked into the gap, a vacuum treatment is done, and then removed to cool. Its principle is shown in Figure 1.

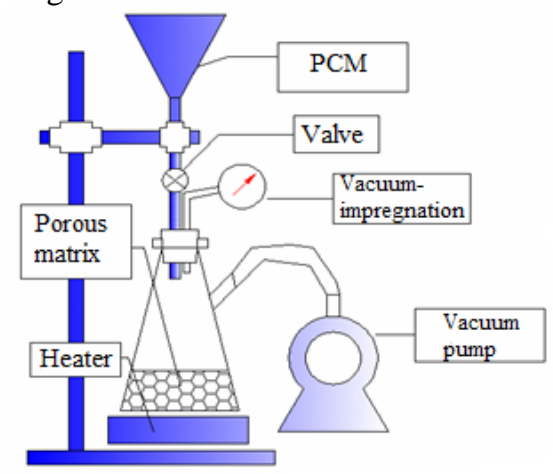

Fig. 1. The principle of vacuum impregnation method

Vacuum impregnation method is usually to make phase change materials immersed in porous matrix better, and to prepare composite phase change material with extremely excellent performance. Therefore, there are a lot of researchers to prepare porous composite phase change materials with this method during the recent years. i.e. Ahmet Sari and AliKaraipekli [6] prepared palmitic acid/expanded graphite composite phase change material by vacuum impregnation method, its thermal cycle test pointed out that after heat storage cycles of 3000 times the composite phase change material still maintained good thermal performance. M. Li et al [7] studied araffin/expanded perlite composite phase change material, the research results showed that its vacuum adsorption could make paraffin distribution more uniform in pearlite. $\mathrm{H}$. He et al[8] investigated fatty acid/sludge ceramsite composite phase change material by 
vacuum impregnation method, its investigation results showed that it is suitable for energy efficiency in buildings and can realize the recycle of solid waste mud.

Preparing porous composite phase change materials by vacuum impregnation method can greatly improve the adsorption rate of porous matrix for phase change materials, simultaneously which can reduce the leakage rate of phase change materials, and make their heat storage performance improved markedly, especially still keep a good stability after many thermal cycles. However, its preparation mostly stays in the stage of laboratories, in order to make it industrial production expansion; more technical support must be still needed. How to reduce the production cost should be the main research direction in the future.

\section{Selection of Porous Matrixes}

As for the selection of porous matrixes, the structural characteristics (such as size distribution, shape and connectivity of pores etc) and the compatibility with phase change materials usually need to be considered. There are mainly three types of porous matrixes to be selected, including porous inorganic matrixes, porous metal matrixes, and expanded graphite matrixes.

\subsection{Porous inorganic matrixes}

Porous inorganic matrixes are the orderly porous skeleton made of all inorganic compounds. Phase change materials are adsorbed in the porous inorganic matrixes, while the phase transition of phase change materials takes place, or solid-liquid phase change occurs in the microscopic range, but the phase change materials still keep the original shape in the macroscopic range, and have no leakage and overflow from the matrixes. Porous inorganic matrixes have such characteristics as appropriate porous structure and good adsorption performance, but most of them have lower application temperature and structural strength, thus limiting the scope of utilization. Porous ceramics is used widely in porous inorganic matrixes because of its performances such as higher temperature and oxidation resistance etc, as shown in Figure 2. Porous inorganic matrixes can be composite with inorganic phase change materials, i.e. Z.W. Ge et al[9] used eutectic mixture of sodium carbonate lithium as phase change material and ceramic as matrix, a certain amount of graphite was added to improve the performance of thermal conductivity, then prepared composite phase change material with excellent performance. R. P. Liu et al [10] studied sodium carbonate/porous mullite composite phase change material, and tested its heat storage performance. Moreover, porous inorganic matrixes can be also composite with organic phase change materials, i.e. X.F. Zhou et al [11] 
incorporated paraffin/porous ceramic composite phase change material, and its adsorption rate of paraffin in the porous ceramics could reach $75 \%$. M. Li et al [12] developed paraffin/bentonite composite phase change material, its melting point was close to that of paraffin wax and its thermal conductivity was better than bentonite.

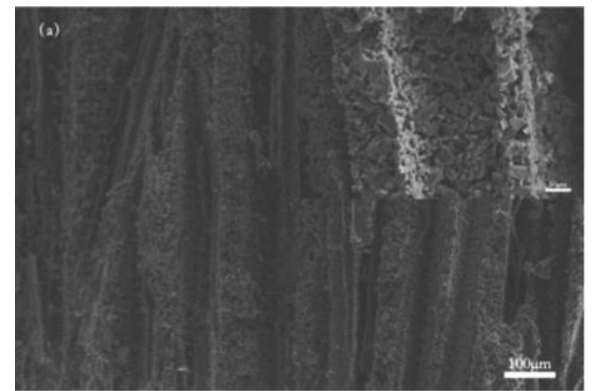

(a) Side view

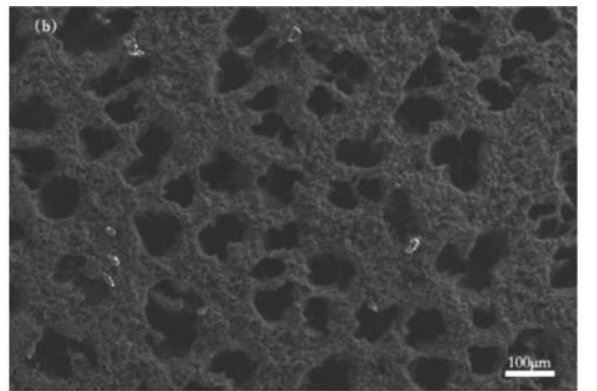

(b) Sectional view

Fig. 2. The SEM images of porous ceramics

Composite phase change materials are prepared by using porous inorganic matrixes, which has such characteristics as higher storage content, better thermal performance and good strength similar to porous inorganic matrixes. In addition, their stable chemical properties can make porous inorganic matrixes composite with a variety of phase change materials, and improve their application scope, but they have lower application temperature and generally worse heat conduction performance, which is needed to add some metal elements to improve their thermal performance.

\subsection{Porous metal matrixes}

Porous metal matrixes are also called foam metal matrixes; they have such characteristics as smaller density, higher specific surface area, higher porosity, lighter quality, excellent permeability etc, as shown in Figure 3. With the development of technique during the recent years, the drawback of poor thermal stability and chemical stability of porous metal matrixes has been gradually overcome. Therefore, porous metal matrixes such as bronze, nickel, titanium, stainless steel, and other metals and alloys have been widely used. In their theory, A. Bhattacharya et al[13] thought that there was certain correlation between porosity and thermal conductivity coefficient of foam metal matrixes after having analyzed the theoretical model entirely, and the specific surface area of foam metal matrixes was also related to their thermal conductivity coefficient. O. Mesalhy et al [14] established the relevant mathematical model based on the three equilibrium equations in fluid mechanics, and the simulation results showed that, the porous foam metal matrix had a great influence on heat 
storage performance and latent heat of phase change materials, and higher porosity and thermal conductivity coefficient of porous foam metal matrix is the best choice of phase change material. C.H. Son [15] prepared neopentyl glycol/aluminum foam composite phase change material; the test showed that its thermal conductivity coefficient increased 10-60 times. Y. Tian and C.Y. Zhao [16] studied heat transfer enhancement of metal foam phase change material by the numerical method, and the numerical results had been verified by the experiment.

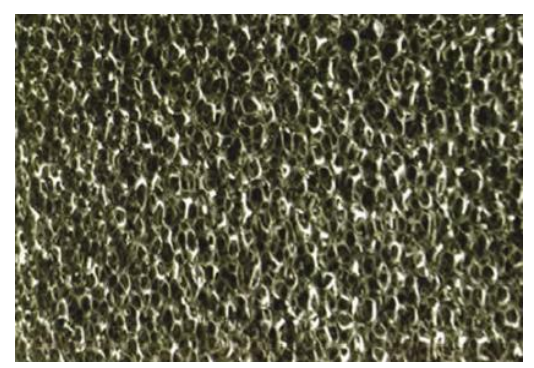

Fig. 3. The SEM image of foam copper

Composite phase change materials are prepared by using porous metal matrixes, which makes heat conduction performance improved greatly, metal matrixes and phase change materials can be combined better, and their heat storage performance may be increased obviously, but the selection of metal matrixes and phase change materials has many restrictions, their chemical properties are extremely unstable, thus the wide applications still have a lot of technical problems that need to solve.

\subsection{Expanded graphite matrixes}

Expanded graphite matrixes shown in Figure 4, are made of a porous puffed wormlike substances obtained from natural flake graphite through intercalating, washing, drying, high temperature expansion, in which graphite surface layer is obvious original crack and uneven deformation, the surface layer is curly and its surface is the mesh structure after high temperature expansion. Expanded graphite matrixes retain the fine properties of natural flake graphites such as good thermal conductivity, non-toxic, and also have such characteristics as no adsorption, ecological environment coordination and biocompatibility etc. Expanded graphite matrixes have been investigated during the recent years, i.e. Ahmet Sari and All Karaipekli [17] prepared 4 types of paraffin/expanded graphite composite phase change materials, whose expanded graphite contents were respectively $2 \%, 4 \%, 7 \%$ and $10 \%$, compared the differences of their phase transition temperature, latent heat, thermal conductivity and leakage situation of paraffin wax, the composite phase change material with $10 \%$ mass fraction of 
expanded graphite was form-stable, smaller density, higher thermal conductivity, without encapsulation, and suitable for latent heat energy storage. J. B. Xiao et al[18] mixed binary nitrate and expanded graphite to obtain binary nitrate/expanded graphite composite phase change material, in which the binary nitrate was seeped into the expanded graphite to improve the performance of thermal conductivity but its latent heat wasn't affected. C. Liu, et al[19] developed 12-14 stearic acid/expanded graphite composite phase change material, which still kept good thermal stability after the melting solidification cycle test of 1000 times. Seul-Yi Lee et al [20] studied erythritol/expanded graphite composite phase change material by vacuum adsorption method, the test results showed that its thermal conductivity and stability were improved, and had a suitable latent heat.

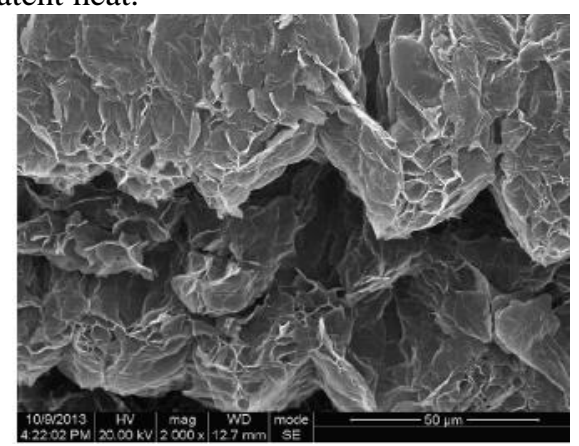

Fig. 4. The SEM image of expanded graphite matrix.

Composite phase change materials are prepared by using expanded graphite matrixes, which maintain the original porous vermiform structure, phase change materials can be dissolved in expanded graphite uniformly, and their phase transition temperature is similar to the pure phase change materials. Since expanded graphite matrixes have excellent thermal performance, their heat storage time is still less than the pure phase change materials. Composite phase change materials prepared by using expanded graphite have not only improved their thermal conductivity, but also solved the liquid flow problem while applied.

\section{Applications of Porous Composite Phase Change Materials}

Since porous phase change materials have such characteristics as simpler preparation technique and good heat storage and discharge performance, they have been widely applied in many fields. 


\subsection{Applications on energy saving in buildings}

Porous phase change materials combined with architectural materials can not only decrease effectively energy consumption to realize energy-saving in buildings, but also achieve the function of adjusting comfortable indoor environment temperature in buildings, i.e. H. Lu et al[21] prepared a fatty acidparaffin/expanded perlite composite phase change material and mixed the phase change material and slurry, the DSC and SEM analysis results showed that fatty acid was entered into the microporous expanded perlite and its thermal performance was not affected, the paraffin package effect was good, and the new slurry with composite phase change material could improve its thermal performance effectively. Z. F. Liu[22] selected lauric acid and dodecanol binary eutectic melt as phase change materials as well as expanded perlite as a carrier, prepared phase change thermal storage concrete of building energy-saving, its energy storage effect and mechanical properties were tested. A.Z.Deng et al[23] studied on applying phase change material wall to the light weight envelope solar house, the experimental results indicated that phase change material as the constitute part of wall body can enlarge the cumulate thermal capability of light steel structure and hot sloth index, and can charge and discharge the solar energy effectively.

\subsection{Applications on energy saving in the other fields}

Since porous phase change materials have good temperature control performance, they have been widely utilized in the other fields, i.e. Y.F. Shen et al [24] found that using phase change materials in combination with the foaming material could effectively improve their thermal conductivity, applied to the thermal management system of electric car lithium-ion battery could guarantee the lithium ion battery under the suitable temperature, and maintained the uniformity between the cells. J. Huang [25] developed inorganic salt/ceramic composite phase change material, and made this material into spherical components in packed bed regenerator as waste heat recovery system of industrial heating system. In addition, porous phase change materials can also be used for air conditioning refrigeration, its principle is that porous graphite matrixes composite with the eutectic mixture of tetradecane, pentadecane and hexadecane to form composite phase change materials whose phase transition temperature is slightly lower about $7-12^{\circ} \mathrm{C}$ than air conditioning water, thus they can be used for air conditioning refrigeration [26]. 


\section{Conclusion}

Based on investigation and exploitation during the recent years, the preparation of porous phase change materials by using phase change materials composite with porous matrixes has been developed greatly. Along with continual development of society economy and science technology, the requirement of environment is being higher and higher, the preparation of porous phase change materials by using phase change materials composite with porous matrixes will be developed continuously, they should be widely used in the fields of energysaving in buildings and multi-industries.

\section{References}

1. H.O. Wang, C.Y. Miu, and Y.W. Yao, et al.: Review on phase change materials. Functional Materials (in Chinese), Vol. 38 (2007), pp. 1577-1581

2. X.Q. Zhu, J.Hu, and Y.F. Yang, et al.: Applications of enhancement techniques in investigations of phase change energy storage materials. Materials Review (in Chinese), Vol. 22 (2008), pp. 87-89.

3. G.A. Lane: Solar Heat Storage: Latent Heat Materials. Vol. I. Background and Scientific Principles (Florida: CRC Press, 1983).

4. H. Kaasinen: The absorption of phase change substances into commonly used building materials. Solar Energy Materials and Solar Cells, Vol. 27 (1992), pp. 173-179.

5. T. Lee, D. W. Hawes, and D. Banu, et al.: Control aspects latent heat storage and recovering in concrete, Solar Energy Materials and Solar Cells, Vol. 62 (2000), pp. 217-237.

6. Ahmet Sarl, AliKaraipekli: Preparation, thermal properties and thermal reliability of palmitic acid/expanded graphite composite as form-stable PCM for thermal energy storage. Solar Energy Materials and Solar Cells, Vol. 93 (2009), pp. 571-576.

7. M. Li, Z.S. Wu, M.R. Chen: Preparation and properties of gypsum-based heat storage and preservation material. Energy Building, Vol. 43 (2011), pp. 2314-2319.

8. H. He, P. Zhao, and Q. Yue, et al.: A novel polynary fatty acid/sludge ceramsite composite phase change materials and its applications in building energy conservation. Renewable Energy, Vol. 4 (2015), pp. 45-52.

9. Z.W. Ge, F. Ye, and H. Cao: Carbonate salt based composite materials for medium and high temperature thermal energy storage. Particuology, Vol. 15(2014), pp.77-81. 
10. R.P .Liu, F. Zhang, W.M. Su: Impregnation of porous mullite with $\mathrm{Na}_{2} \mathrm{SO}_{4}$ phase change material for thermal energy storage. Solar Energy Materials and Solar Cells, Vol.134 (2015), pp.268-274.

11. X. F. Zhou, H. N .Xiao, J. Feng: Preparation and thermal properties of paraffin/porous silica ceramic composite. Composites Science and Technology, Vol.69 (2009), pp.1246-1249.

12. M. Li, Z. S. Wu, H.T. Kao: Experimental investigation of preparation and thermal performances of paraffin/bentonite composite phase change material. Energy Conversion and Management, Vol.52 (2011), pp.32753281 .

13. A. Bhattacharya, V.V. Calmidi, R. L .Mahajan: Thermo physical properties of high porosity metal foams. International Journal of Heat and Mass Transfer, Vol.45 (2002), pp.1017-1031.

14. O. Mesalhy, K. Lafdi, A. Elgafy, et a1: Numerical study for enhancing the thermal conductivity of phase change material (PCM) storage using high thermal conductivity porous matrix. Energy Conversion and Management, Vol.46 (2005), pp.847-867.

15. C. H. Son, J. H. Morehouse: Thermal conductivity enhancement of solidsolid phase-change materials for thermal storage. Journal of Thermophysics and Heat Transfer, Vol.5 (1991), pp.122-124.

16. Y. Tian, Y. C. Y .Zhao: Anumerical investigation of heat transfer in phase change materials embedded in porous metals. Energy, Vol.36 (2001), pp.5539-5546.

17. Ahmet Sari, All Karaipekli: Thermal conductivity and latent heat thermal en energy storage characteristics of paraffin/expanded graphite composite as phase change material. Applied Thermal Engineering, Vol.27 (2007), pp.1271-1277.

18. J. B. Xiao, J. Huang, and P. P. Zhu: Preparation, characterization and thermal properties of binary nitrate salts/expanded graphite as composite phase change material. Thermochimica Acta, Vol.587 (2014), pp.52-58.

19. C. Liu, Y. P. Yuan, N. Zhang: A novel PCM of lauric-myristicstearicacid/expanded graphite composite for thermal energy storage. Materials Letters, Vol.120 (2014), pp.43-46.

20. Seul-Yi Leea, Hye Kyoung Shina, Mira Park: Thermal characterization of erythritol/expanded graphite composites for high thermal storage capacity. Carbon, Vol.68 (2014), pp.67-72.

21. H. Lu, X .Zhang, Y. J. Zhang: New Building Materials (in Chinese). Vol.21 (2010), p.21. 
22. Z. F. Liu: Study on phase change thermal storage concrete of building energy-saving. Ready-mixed Concrete (in Chinese), Vol.22 (2011), pp.3840.

23. A. Z. Deng, C.L. Zhang, S. B. Li, et al: Study on applying PCM wall to the light weight envelope solar house. Acta Energiae Solais Sinica(in Chinese), Vol.32(2011), pp.160-164.

24. Y. F. Shen, J. W. Cheng, J.Wang: Application research of PCM on thermal management system of lithium ion battery package. New Energy Vehicles (in Chinese), Vol.11 (2011), pp.3-6.

25. J. Huang: Study on composite phase change energy storage materials by molten salt spontaneous infiltrating porous ceramic performs. $\mathrm{PhD}$ thesis, Guang Dong University of Technology (in Chinese), 2005.

26. S. L. Tian, D. W. Zhang, D. Yan. Xiao: Experimental investigation on shape-stabilized phase change material of stearic acid butyl ester/ porous graphite. Energy Conservation (in Chinese), Vol.11 (2005), pp.5-6. 